\title{
Sensibilidade cívica e cidadania no Brasil'
}

\section{Civic sensibility and citizenship in Brazil}

\section{Luís R. Cardoso de Oliveira}

Professor titular livre de Antropologia na Universidade de Brasília e doutor pela Universidade de Harvard. Seu livro mais recente é Desvendando evidências simbólicas: compreensão e conteúdo emancipatório da Antropologia, publicado em 2018 pela Editora da UFRJ. Suas pesquisas têm como foco processos de administração de conflitos e demandas por direitos de cidadania em perspectiva comparada: Brasil, Estados Unidos, Canadá/Quebec e França.

\section{Resumo}

O artigo desenvolve o conceito de sensibilidade cívica para discutir a ideia de igualdade cidadã com foco no Brasil. Tendo como referência demandas por respeito e consideração ou reconhecimento, o texto propõe que a igualdade cidadã, onde quer que ela se realize, seja sempre modulada pela relação entre direitos, status e dignidade, configurando sensibilidades cívicas locais, caracterizadas por um determinado senso de tratamento digno, que não inferioriza o interlocutor no plano da dignidade.

Palavras-chave: Concepções de Igualdade, Dignidade, Mundo Cívico, Comparação, Legitimidade.

\section{Abstract}

This article develops the concept of civic sensibility to discuss the idea of citizen equality with a focus on Brazil. Referring to demands for respect and consideration or recognition, the text proposes that citizen equality, wherever it takes place, is always modulated by the relation between rights, status and dignity, shaping local civic sensibilities, characterized by a certain sense of dignified treatment, which does not make the interlocutor inferior in his or her dignity.

Keywords: Conceptions of Equality, Dignity, Civic World, Comparison, Legitimacy.

Fiz uma conferência com o mesmo título no Departamento de Antropologia da Universidade Estadual de Campinas (UNICAMP) em novembro de 2017, e outra com título similar em abril deste ano no Programa de Pós-Graduação em Antropologia e Sociologia da Universidade Federal do Pará (UFPA). Agradeço as duas instituições pela oportunidade de avançar minhas reflexões sobre o tema, e a Wilson Trajano Filho pelos comentários a uma versão preliminar do texto. 
A noção de cidadania e os direitos a ela associados talvez sejam os principais símbolos das democracias no ocidente, e aqueles que melhor representam a ideia de igualdade como um valor nestas sociedades. Se a definição dos direitos básicos de cidadania (civis, políticos e sociais) sugeriam procedimentos claros e uniformes para a sua institucionalização, o acirramento e a visibilidade das demandas de reconhecimento a partir do último quartel do século passado complexificaram bastante a compreensão da relação entre os termos desta equação e suas implicações para o exercício da cidadania. Se o reconhecimento da singularidade de grupos sociais específicos passa a ser visto como uma condição para o respeito à cidadania dos respectivos grupos, como caracterizar a ideia de igualdade cidadã?

Além disso, as demandas por reconhecimento trazem à tona uma dimensão dos direitos em grande medida encoberta até então, quando olhamos para as interações sociais no âmbito do que poderíamos identificar como o mundo cívico ${ }^{1}$. Refiro-me à dimensão dos direitos indissociável da qualidade da relação entre as partes, e que remete a percepções sobre a dignidade do cidadão, fazendo com que a igualdade cidadã tenha que articular satisfatoriamente direitos e status/identidades para contemplar demandas legítimas de respeito e consideração ou reconhecimento. Como tal articulação se dá de forma diversa em diferentes sociedades, proponho que a igualdade cidadã, onde quer que ela se realize, seja sempre modulada pela relação entre direitos, status/identidade, e dignidade, configurando sensibilidades cívicas locais, caracterizadas por um determinado senso de tratamento digno, que não inferioriza o interlocutor no plano da dignidade ${ }^{2}$.

Nestes termos, a contribuição de Marshall (1976) sobre a indissociabilidade da relação entre direitos e status na configuração da igualdade cidadã,

\footnotetext{
O mundo cívico é constituído pelo universo de relações fora do espaço doméstico ou da intimidade onde o status ou condição de cidadão deve ter precedência e o tratamento igualitário, geralmente uniforme, deve ser a regra.

2 A noção de sensibilidade cívica é claramente inspirada na formulação de Geertz (1983) sobre a existência de diferentes sensibilidades jurídicas, que estariam associadas a sensos de justiça específicos. Lembro ainda que a noção de cidadania, assim como a igualdade de status decorrente, é contemporânea da transformação da noção de honra em dignidade, na passagem do regime antigo para a sociedade moderna (TAYLOR, 1994).
} 
assim como a observação de d'Iribarne (2010, p. 35-79) sobre a diferença ente direitos e dignidade na composição da igualdade cidadã na França, sugerem a necessidade de complexificação da noção de igualdade de tratamento proposta por Honneth (2007, p. 99-128) $)^{3}$, para caracterizar o cerne da democracia e da cidadania no ocidente. Pois a variação entre concepções de igualdade e cidadania demandaria um quadro analítico mais dinâmico, como o que estou propondo aqui através da noção de sensibilidade cívica.

\section{DEMANDAS DE RESPEITO, CONSIDERAÇÃO E RECONHECIMENTO}

Diferenças na relação entre direitos e cidadania começaram a chamar minha atenção ao contrastar dilemas da cidadania no Brasil e nos EUA no início dos anos 1990. A ênfase estadunidense no respeito aos direitos do indivíduo genérico, o unencumbered self (SANDEL, 1984, p. 81-96) ou sujeito sem vínculos, contrastava de forma acentuada com a preocupação brasileira em expressar consideração à pessoa do cidadão (CARDOSO DE OLIVEIRA, 1996, p. 67-81), fazendo com que, neste último caso, os atores tivessem dificuldade de respeitar direitos dos interlocutores nos quais não identificavam a substância moral das pessoas dignas (CARDOSO DE OLIVEIRA, 2011a). Já no caso estadunidense, e tendo como referência minha pesquisa sobre juizados de pequenas causas em Massachusetts (CARDOSO DE OLIVEIRA, 1989), a impessoalidade exacerbada fazia com que os atores tivessem dificuldade de respeitar direitos cuja observação demandava expressões de deferência e consideração ao interlocutor ${ }^{4}$. Isto é, refiro-me a causas nas quais a falta de atenção ao interlocutor

\footnotetext{
Na realidade, Honneth procura dar conta da necessária incorporação da dimensão moral do cuidado com os outros (Fürsorge) e do lugar das relações assimétricas no ponto de vista moral da modernidade, usualmente circunscrito pela ideia de tratamento igualitário. Contudo, ao limitar sua discussão ao diálogo com a tradição filosófica com foco nas relações de amizade, especialmente com os trabalhos mais recentes de Derrida, sua proposta não dá conta dos aspectos sociológicos ou etnográficos que caracterizam as demandas de tratamento igualitário que efetivamente têm lugar nos contextos analisados aqui.

4 Refiro-me ao que gostaria de chamar de deferência cívica, caracterizada pela expressão de reconhecimento da dignidade do interlocutor, com quem compartilha o mesmo status no mundo cívico.
} 
era vivida como um insulto pelas partes, que gostariam de obter reparação pela qualidade da interação que lhes teria sido imposta, colocando-os numa condição de inferioridade, inaceitável no plano da cidadania.

Tal quadro sugeria que Brasil e Estados Unidos tinham déficits de cidadania em direções opostas, ainda que no Brasil o problema fosse mais acentuado devido à dificuldade de respeitar direitos básicos de cidadania. Na mesma direção, a comparação também sugeria que qualquer que fosse a configuração local da cidadania, para que esta se realizasse de maneira adequada, seria necessária a produção de um equilíbrio entre o respeito aos direitos e a consideração à pessoa do cidadão.

Num segundo momento, para levar adiante a reflexão sobre esses dilemas, incluí o Quebec no quadro comparativo. A demanda de reconhecimento da província como uma sociedade distinta no interior do Canadá complexificava a relação entre respeito e consideração no contraste entre Brasil e Estados Unidos, ao explicitar a importância da expressão de apreço às contribuições da cultura francófona na formação do país, e assim viabilizar o resgate da dignidade de seus concidadãos que demandam reconhecimento. Aqui, a percepção de igualdade, no plano da dignidade ou do status da cidadania, demandava a afirmação do valor ou mérito singular do grupo para que seu lugar na sociedade não fosse vivido como uma condição de inferioridade ${ }^{5}$. O caso canadense/ quebequense sugere que ao lado dos direitos básicos de cidadania, deveríamos levar em conta também indicadores de dignidade básica do cidadão como aspectos igualmente constitutivos das concepções de igualdade vigentes e das condições de legitimação da democracia na vida cotidiana dos atores.

Se a importância do status ou da identidade para o exercício da cidadania, e suas conexões com a substância moral da dignidade (CARDOSO DE OLIVEIRA, 2011a), é explicitada etnograficamente nas demandas de consideração e reconhecimento, que iluminam respectivamente os casos do Brasil

\footnotetext{
O que Taylor (1994) caracteriza como necessidade de reconhecimento de uma identidade autêntica, me parece melhor formulado a partir da ideia de substância moral da dignidade (CARDOSO DE OLIVEIRA, 2011a). Enquanto a ideia de autenticidade sugere a referência a conteúdos específicos, a noção de substância moral indica maior flexibilidade na definição do(s) conteúdo(s) que lhe daria(m) suporte, e acentua o aspecto convencional deste(s).
} 
e do Canadá/Quebec, o caso do republicanismo francês traz um viés interessante para o problema ao situar a dignidade no cerne da concepção de igualdade dominante na França ${ }^{6}$. Segundo d'Iribarne (2010, p. 35-79) o exercício da cidadania na França expressaria uma composição republicana entre um corpo político (concebido como um espaço sagrado e espiritual) e um corpo social (concebido como o espaço da vida cotidiana). Enquanto no primeiro teria vigência uma condição de igualdade radical entre os cidadãos (sufrágio universal, cada cidadão um voto), o segundo abrigaria uma série de desigualdades contingentes: e.g., profissões mais ou menos nobres (cadres versus non-cadres) com direitos diferenciados (de férias, pensões etc.). Mas, contanto que estas diferenças garantissem o mesmo respeito a todas as profissões, a dignidade de todos estaria igualmente resguardada. Na mesma direção, d'Iribarne caracteriza esta percepção de igualdade no plano da dignidade como a possibilidade de participar, de forma compartilhada, da noblesse na França (2006, p. 53). Tal participação não expressaria necessariamente qualquer vínculo com a nobreza, mas enfatizaria a condição ou percepção de partilhar do espírito, da razão e da ordem vigentes na França, em oposição a tudo aquilo que corrompe, suja, desorganiza e polui a sociedade.

De todo modo, como quer que seja articulada a demanda de atenção aos direitos de cidadania, via as ideias de respeito (EUA), de consideração (Brasil) ou de reconhecimento (Quebec), as respectivas concepções de igualdade que lhes dão suporte dependem de sentidos substantivos expressos em sensibilidades cívicas locais, que modulariam a relação percebida como adequada entre direitos, status e dignidade. Se, em suas manifestações empíricas, cada uma destas ideias pretende englobar as demais na definição vigente de igualdade cidadã, no plano conceitual elas apontam para dimensões importantes da cidadania e para a indissociabilidade fenomenológica entre igualdade, dignidade e equidade nas democracias ocidentais (CARDOSO DE OLIVEIRA, 2013).

\footnotetext{
Mota (2014, p. 185) também chama a atenção para a importância da relação entre igualdade e dignidade na França, em sua interessante etnografia ao comparar demandas de direitos e reconhecimento no Brasil e na França.
} 
Na mesma direção, se a ideia de respeito (respect) vigente nos Estados Unidos é a que melhor caracteriza a ênfase na igualdade de direitos ${ }^{7}$, esta é apenas uma dimensão da sensibilidade cívica que caracterizaria a igualdade cidadã e o sentido de tratamento igualitário que preocupa Honneth, como indicador de qualidade da democracia. Para pintar um quadro mais claro da importância da noção de sensibilidade cívica com o objetivo de compreender os dilemas da cidadania, com foco no Brasil, no que se segue vou (a) introduzir a tensão entre duas concepções de igualdade vigentes no país e suas implicações para a cidadania, para em seguida (b) contrastar com o dilema canadense para equacionar direitos e status/identidade na formulação de uma concepção de igualdade cidadã que possa ser amplamente compartilhada no Quebec e no resto do Canadá. Finalmente, vou concluir o artigo (c) com uma breve discussão sobre, por um lado, a distinção entre transparência e falta de clareza nas ações do Estado brasileiro e, por outro, sobre a separação entre moralidade societária ou de civilidade ${ }^{8}$ democrática e moralidade comunitária entre nós. Como ficará claro adiante, a singularidade brasileira estaria na confusão entre direitos e privilégios, decorrente da tensão entre as duas concepções de igualdade, impedindo a definição de um mundo cívico bem conformado.

\section{A TENSÃO ENTRE DUAS CONCEPÇÕES DE IGUALDADE NO BRASIL}

Depois de ter chamado a atenção para a dificuldade brasileira em distinguir interesses sociais (amplamente universalizáveis) e interesses corporativos ou sindicais (com abrangência sempre circunscrita), ao lado de certa desarticulação entre espaço público e esfera pública no Brasil (CARDOSO

\footnotetext{
A ideia de respeito, cujo cerne aparece de forma clara e cristalina no contexto estadunidense, é também a ideia acionada com maior vigor nas diversas tradições ocidentais que abordam o tema da cidadania no que concerne aos direitos: Achtung (Alemanha), respect (França), respeto no mundo hispânico, respeito em português etc.

8 Agradeço a Roberto Kant de Lima por me chamar a atenção para a importância da ideia de civilidade, neste contexto, para acentuar o contraste com a ideia de moralidade cívica, com ênfase no patriotismo, que vigorou durante a ditadura civil-militar entre 1964 e 1985.
} 
DE OLIVEIRA, 2011a, p. 129-171)9 , passei a identificar também a existência de uma tensão entre duas concepções de igualdade, tendo como consequência uma confusão significativa entre o acesso a direitos e privilégios no país (CARDOSO DE OLIVEIRA, 2011b, 2013). Se, por um lado, a concepção de igualdade dominante em nossa Carta Constitucional de 1988 enfatiza a igualdade de direitos entre os cidadãos, bem expressa na ideia de isonomia jurídica, por outro lado, também tem vigência em nossa esfera pública e práticas institucionais uma segunda concepção, bem representada na famosa frase de Rui Barbosa, acionada com frequência por autoridades de todos os matizes: "A regra da igualdade não consiste senão em quinhoar desigualmente aos desiguais, na medida em que se desigualam" (BARBOSA, 1999, p. 26).

Embora estas duas concepções sejam frequentemente vistas como aspectos de uma mesma visão de mundo e plenamente coerentes entre si, a segunda concepção, expressa na frase de Rui Barbosa, apresenta uma característica incompatível com o cerne da ideia de cidadania dominante no ocidente em qualquer de suas manifestações. Pois, se a igualdade cidadã implica sempre um equilíbrio entre direitos e status como símbolos de igualdade, conforme sensibilidades cívicas locais, a regra proposta por Barbosa sugere uma forma de "tratamento igualitário" na qual os direitos seriam diferenciados (ou desigualados) de acordo com o status do cidadão ${ }^{10}$. O exemplo mais claro e conhecido de sua incidência em nossa estrutura normativa é o instituto da "prisão especial" (antes da condenação do acusado) para portadores de diploma de curso superior, distinguindo direitos de acordo com o status social do cidadão ${ }^{11}$. Como veremos mais adiante, tal concepção contrasta fortemente com a demanda de distinção quebequense, onde a reivindicação de direitos diferenciados na

9 Caracterizados respectivamente como universo de interação e universo de interlocução sobre a definição de regras, normas, projetos e visões de mundo. Enquanto neste haveria um certo consenso sobre a igualdade de direitos, no primeiro abundariam as demandas por tratamento privilegiado.

${ }^{10}$ Mesmo que esta não seja, eventualmente, a melhor interpretação da proposta de Rui Barbosa, meu argumento é de que esta seria a interpretação que dá sentido às situações em que a frase é acionada para desigualar direitos.

${ }^{11}$ Veja o ensaio de Teixeira Mendes (2005) sobre igualdade à brasileira. Na realidade, o acesso à prisão especial foi ampliado nos últimos anos, e abrange outras categorias além dos portadores de diploma superior. Embora este não seja o único exemplo de alocação de direitos conforme o status social do cidadão, é o mais conhecido e aquele que melhor expressa problema. 
província é motivada pela pretensão de obter tratamento igualitário no plano do status ou da dignidade cidadã.

De todo modo, um reflexo imediato da tensão entre as duas concepções de igualdade no cotidiano do exercício da cidadania no Brasil é a confusão entre os campos semânticos de direitos e privilégios nas mais diversas práticas e situações sociais. Pois, se a cidadania pode ser definida como condição que articula direitos e status igualitários no mundo cívico, como quer que os mesmos sejam concebidos, como admitir direitos diferenciados com referência à desigualdade de status no plano da cidadania? Se definirmos privilégio como um direito especial, sempre que sua aplicação ou exercício estiver associada ao status social do ator, as práticas ou instituições que legitimariam seu acionamento devem estar situadas fora do mundo cívico, ou do universo de interações onde a condição de cidadão deve ter precedência. Um bom exemplo para caracterizar este ponto seria a manifestação do Rei Juan Carlos da Espanha, antes de abdicar em favor do filho, ao se pronunciar sobre as acusações contra seu genro Iñakli Urdangarin - duque de Palma Maiorca - que estaria envolvido em atos de corrupção e desvio de recursos públicos. Segundo ele, naquela matéria seu genro deveria ser julgado como qualquer outro cidadão ${ }^{12}$. Isto é, os privilégios aos quais o genro teria direito como membro da nobreza não poderiam ser acionados em relação a práticas situadas no mundo cívico.

Já entre nós, ou em nosso espaço público, não faltam exemplos em que a tensão entre as duas concepções de igualdade vigentes provoca confusão e conflito de expectativas entre os atores: seja no acionamento de regras ou leis que dão acesso a direitos; no comportamento esperado dos atores em interação; ou, no tratamento recebido em nossas instituições públicas. Neste sentido, chamei atenção para o debate em torno de projetos de lei que aboliam a restrição de acesso a elevador/entrada social em condomínios residenciais por parte de empregadas domésticas nas cidades brasileiras (CARDOSO DE OLIVEIRA, 2011b, 2013).

\footnotetext{
12 Veja a reportagem "Rei da Espanha exalta em discurso que justiça é igual para todos" publicada no Portal Terra, em 24 de dezembro de 2011. Disponível em: https://goo.gl/y8ABK2. Acesso em: 25 set. 2018.
} 
Em cidades como o Rio de Janeiro, por exemplo, os prédios residenciais têm entradas de serviço e social, sendo esta última para uso exclusivo de moradores e de suas visitas. Empregadas domésticas e serviçais são encaminhadas para a entrada/elevador de serviço. Argumentei então que até período relativamente recente tal separação não era vivida como um ato de desrespeito ou desconsideração à dignidade de empregadas e serviçais, que não se sentiam necessariamente ofendidos quando orientados a observar esta regra. Não obstante, os argumentos em defesa do projeto de lei que elimina a restrição de acesso à entrada/elevador social, assim como aqueles divulgados em reportagens televisivas sobre o tema, sugerem que a sustentação do privilégio atribuído a moradores e visitantes na utilização da entrada social perdeu justificação discursiva, e passa a ser vivido como um símbolo de exclusão no plano da cidadania, provocando inclusive experiências de humilhação ${ }^{13}$, ainda que as entrevistas apresentadas nas respectivas reportagens revelem o caráter controverso do tema, com discursos favoráveis e contrários à medida.

Em outras palavras, a igualdade de direitos no acesso à entrada social passa a ser parte do mundo cívico aos olhos de contingentes expressivos da população, onde se espera tratamento igualitário, geralmente uniforme, entre os atores. Assim, este seria um bom exemplo do agravamento da tensão entre as duas concepções de igualdade indicadas, e caracterizaria bem a confusão entre o exercício de direitos e privilégios no espaço público brasileiro, indicando a existência de um mundo cívico mal conformado.

Evidentemente, para além de casos como o da discussão do projeto de lei mencionado, onde o assunto é tema de argumentação normativa, há um amplo universo de situações nas quais a tensão entre concepções de igualdade e a desarticulação entre esfera (campo argumentativo) e espaço (campo interativo) públicos aparecem de forma fortemente imbricada. Desde o clássico ato de furar fila, passando por situações diversas de discriminação cívica, até o acionamento claramente arbitrário das leis e regras de comportamento.

\footnotetext{
${ }_{13}$ Como no caso descrito por um transeunte entrevistado na reportagem: "Ela estava com um embrulho na mão. Foi solicitado para que ela se retirasse do elevador. Ela saiu chorando. Chegou no apartamento muito constrangida, passou por constrangimento ilegal imenso" (CARDOSO DE OLIVEIRA, 2011b, p. 45).
} 
Embora seja cada vez mais difícil furar fila impunemente nos espaços públicos ou reivindicar tratamento especial acionando a famosa frase "você sabe com quem está falando"14, pois aqueles que o fazem passaram a ser questionados com veemência. Há poucos anos ganhou manchete nos jornais o caso de um ministro do Superior Tribunal de Justiça que, apesar de não ter furado a fila, exigiu a demissão do estagiário que aguardava a vez atrás dele por ter se recusado à sair da fila do caixa eletrônico do Banco do Brasil no Tribunal enquanto o ministro concluía sua transação. Alegando prerrogativa de foro, o ministro não queria compartilhar o espaço com mais ninguém (!) e se dirigia rispidamente ao estagiário: "Saia daqui, saia daqui, estou fazendo uma transação bancária" ${ }^{15}$.

Vale insistir que os exemplos de desigualdade de tratamento no mundo cívico não se limitam a situações envolvendo demanda de privilégios ou de ações orientadas por regras estabelecidas que definem tratamento diferenciado conforme o status e a condição social do cidadão, mas ocorrem também em práticas de discriminação ou negação de direitos sem qualquer fundamento formal. Como, por exemplo, no caso noticiado pelo jornal O Estado de S.Paulo em 26 de outubro de 2007, no qual uma empregada doméstica de 42 anos, portadora de HIV e identificada como Sueli, foi discriminada em um mercado popular de São Paulo e acabou presa. Ao descobrir que não tinha dinheiro suficiente para pagar tudo que estava levando, retorna às prateleiras para devolver parte da compra e é abordada por um segurança que a acusa de furto e a joga no chão, obrigando-a a acompanhá-lo até uma sala onde ela é novamente agredida.

Após a agressão ela é levada a duas delegacias de polícia em sequência até que a acusação de furto fosse aceita e ela acaba presa. Sua história só virou notícia quando uma advogada em atuação pro bono se interessa pelo caso e consegue livrá-la da prisão dois anos mais tarde! Observe-se, entretanto, que há casos mais graves. Pois, se ela foi aparentemente condenada em primeira instância por uma juíza, cerca de $40 \%$ dos presos no Brasil foram privados de

\footnotetext{
14 Veja o famoso ensaio de Roberto DaMatta com o mesmo título (1979).

15 Reportagem on-line, disponível em: https://goo.gl/Loh1Zk. Acesso em: 29 ago. 2018.
} 
liberdade sem terem sido julgados (KANT DE LIMA; MOUZINHO, 2016, p. 23). Barreto (2007) encontrou em sua pesquisa sobre prisão provisória muitos detentos nesta condição, todos privados de liberdade por tempo muito superior ao limite estabelecido em lei, e muitas vezes sob acusação de crimes que, em caso de condenação, não ficariam tanto tempo presos ou teriam penas alternativas de prestação de serviços à comunidade.

De todo modo, os exemplos de situações nas quais a tensão entre as duas concepções de igualdade vem à tona são muitos, assim como a abrangência do universo no qual o problema está presente. Pois, além dos casos citados, a referida tensão envolve uma série de circunstâncias em que os atores se permitem acionar éticas particularistas, em oposição à Ética universalista que seria esperada no mundo cívico, e que privilegiaria o interesse público nas ações do Estado ou a igualdade de direitos e status entre os cidadãos. Em outro lugar, propus a existência de um continuum onde práticas políticas informadas por éticas particularistas e mais ou menos institucionalizadas poderiam ser classificadas desde o campo da legalidade (liberação de emendas parlamentares pelo executivo em troca de votos), passando por práticas ilegais mas com aceitação social significativa (uso do caixa dois em campanhas políticas), até práticas socialmente execradas, como as que ficaram conhecidas no processo da ação penal 470 no Supremo Tribunal Federal (STF), vulgo mensalão, qualquer que tenha sido a configuração real deste (CARDOSO DE OLIVEIRA, 2010, p. 19-33).

Para não ficar apenas em práticas lideradas por agentes do Estado, poderíamos incluir aqui a prática corrente de optar pelo pagamento com ou sem recibo nas consultas médicas, ou a prática também bastante difundida de piscar o farol nas estradas brasileiras para avisar os motoristas que vem na direção contrária de que há vigilância por radar nas proximidades, e que eles deveriam reduzir a velocidade momentaneamente até passar o radar para não serem multados. Se, num caso, aceita-se a prestação do serviço sem o pagamento de impostos (que beneficiariam o interesse geral) em benefício próprio, no outro relativiza-se a importância da lei, instituída para garantir a segurança nas estradas em prol da cidadania, para expressar solidariedade 
aos demais motoristas trafegando no momento, afirmando a precedência do interesse localizado dos motoristas em detrimento do interesse mais amplo, da sociedade como um todo.

Além de acentuar a confusão entre direito (universalizável) e privilégio (particularizado) no mundo cívico, estes últimos exemplos apontam para a dissintonia entre o que poderíamos chamar de moralidade societária ou de civilidade democrática, por um lado, e moralidade(s) comunitária(s), por outro. Vou retomar este ponto mais à frente, quando contrastar as ideias de transparência e clareza, ou nitidez, ao final do artigo. Antes, porém, vou apresentar a crítica do Quebec à ideia de igualdade como tratamento uniforme para realçar o lugar do status na composição da igualdade cidadã.

\section{DEMANDAS DE RECONHECIMENTO E STATUS IGUALITÁRIO NO QUEBEC}

Desde que a Constituição do Canadá foi patriada (trazida) do Reino Unido e emendada pelo parlamento canadense em 1982 o país vive uma crise constitucional, derivada da recusa do Quebec em subscrever a nova Constituição com a Carta de Direitos e Liberdades que lhe foi anexada. Poucos anos depois de o Canadá ter sido tomado pelos ingleses, cujo domínio foi formalizado em 1763, a promulgação do Ato do Quebec em 1774 permitiu que a província mantivesse o código civil francês, a religião católica e a língua francesa como idioma oficial. Com a intensificação da migração inglesa e a divisão do território em Alto (Ontário) e Baixo Canadá (Quebec) em 1791, o resto do Canadá passou a ser predominantemente anglófono e protestante, além de estar sob a jurisdição da Common Law. Depois de um período repressivo, quando da implantação do Regime do Ato da União entre 1840 e 1867, durante o qual foram feitos esforços de assimilação da população de origem francesa às tradições anglófonas, o Quebec retoma seus direitos culturais com a criação do Domínio do Canadá em 1867, que marca também a data de promulgação da Constituição patriada em 1982. 
A acomodação que viabilizou o acordo em torno da Constituição em 1867 não impediu que o Quebec passasse a maior parte do século XX sem afirmar sua identidade, e sem assumir qualquer protagonismo no enfrentamento do que era percebido como um processo de desvalorização sistemática, ou mesmo de discriminação velada contra a cultura/identidade franco-canadense. Se a Constituição de 1867 tinha devolvido os direitos de acesso à religião católica, ao código civil e à língua francesa, que haviam sido eliminados em 1840, a história subsequente sugere que o direito legal não teria sido acompanhado pela valorização moral que demonstrasse apreço a estas tradições, fazendo com que, aos olhos dos quebequenses, o fim dos esforços de assimilação explícita tivesse sido substituído por processos de assimilação implícita.

Apenas em 1960, com a eleição de Jean Lesage como primeiro ministro da província, tem início a chamada Revolução Tranquila, período no qual são implementadas políticas agressivas de modernização do Estado e de afirmação da identidade nacional. Segundo a literatura até então teria prevalecido a "ideologia estreita da sobrevivência", como desdobramento da derrota dos Patriotas em 1839 (BIBEAU, 1995), que desembocou na implantação do Ato da União mencionado acima. Aliás, tal ideologia é bem expressa na frase reproduzida na placa de todos os veículos do Quebec: Je me souviens ("Eu me lembro"), que tematiza as glórias do passado e os momentos de sofrimento pós-colonização inglesa. Esta lembrança também veio à tona em interlocuções discursivas com anglófonos em Montreal às vésperas do referendum de 1995, quando quebequenses favoráveis ao sim exclamavam: "Nos ancêtres ont souffert ici!" ("Nossos ancestrais sofreram aqui!").

Com a liderança de Lesage, vários slogans da época, — retomados posteriormente na campanha pelo sim, quando do segundo referendum sobre a soberania do Quebec em relação ao resto do Canadá em outubro de 1995 sugerem o enfrentamento ou contestação explícita ao processo de assimilação ao mundo anglófono e a rejeição de atitudes percebidas como de desvalorização do mundo francófono: "Maître chez nous" ("mestres de nós mesmos"), "On est capable" ("nós somos capazes") etc. Este sentimento ou percepção é bem retratado ainda nas primeiras décadas do século XX, com a publicação do 
livro de Leonel Groulx, L'Appel de la race ("O chamado da raça") (1956), talvez o romance nacionalista de maior impacto na província, que conta a estória de um homem de origem franco-quebequense que retorna à província depois de passar anos em Ottawa, casado com uma anglófona e como um advogado de sucesso plenamente integrado ao Canadá inglês.

Este movimento de afirmação da identidade, que desemboca na formulação da demanda de reconhecimento do Quebec como uma sociedade distinta no interior do Canadá, deve ser compreendido como uma rejeição da condição de minoria social na própria província (LEGAULT, 1992), sem autonomia para definir seus anseios e projetos, como os slogans acima indicam. A meu ver, trata-se de uma afirmação de status igualitário, com o mesmo valor e dignidade que seriam desfrutados no resto do Canadá (e/ ou pelos anglófonos) no plano da cidadania. Além desta visão de igualdade ser bem articulada com concepção de país dominante no Quebec, que vê o Canadá como tendo sido formado por dois povos e duas nações ${ }^{16}$, ela remete a vários episódios na história do país, vividos na província como exemplos de tentativas de assimilação implícita ou de desvalorização da cultura e das tradições francesas na formação do país. Embora o resto do Canadá tenha uma visão diferente sobre o acordo de 1867, que viabilizou a formação do país e simboliza a sua identidade, enfatizando a igualdade entre as províncias e seus cidadãos, esta diferença não justificaria a falta de apreço aos franco-canadenses, como é percebida pelo Quebec.

A conscrição ou convocação militar imposta aos franco-canadenses nas duas guerras mundiais, depois de o primeiro ministro à época ter garantido que não o faria unilateralmente, ao lado das limitações impostas ao uso do francês como língua de ensino nas escolas públicas das províncias anglófonas já a partir de 1871, assim como a ausência generalizada de atendimento

\footnotetext{
${ }^{16}$ Como assinala Laforest (1995), esta visão deixou de fazer sentido após as negociações que antecederam o acordo de Charlottetown em 1992, quando as populações autóctones do Canadá (indígenas, esquimós e mestiços), também conhecidas como primeiras nações, ganharam proeminência e sua contribuição para a formação do país passou a ser explicitamente reconhecida. Não obstante, a ideia de que ingleses e franceses, como representantes de duas nações, teriam contribuído igualmente para a formação do país e que o acordo de 1867 teria garantido status igualitário entre eles ainda faz sentido.
} 
em francês na área da saúde no resto do Canadá ${ }^{17}$, são exemplos significativos da percepção de falta de apreço mencionada acima. Entretanto, o insucesso da Comissão Real sobre Bilinguismo e Biculturalismo liderada por Laurendeau (1990) nos anos 1960, quando o governo Trudeau optou pela definição do Canadá como um país multicultural, parece ter repercutido de maneira particularmente dura no Quebec, especialmente quando pensamos na importância da igualdade cidadã englobando direitos e status no mudo cívico ${ }^{18}$.

Como argumento em minha análise do segundo referendum sobre a soberania do Quebec, realizado em outubro de 1995, embora os apoiadores do sim procurassem elencar uma série de iniquidades vigentes nas relações político-econômicas com Ottawa, representando o resto do Canadá, a demanda que angariava maior suporte, e que efetivamente permitiu enorme avanço da opção pelo sim na reta final da campanha, além de contar com simpatia expressiva de seguimentos importantes que votaram pelo não no referendum, era a que focava na crítica ao tratamento desrespeitoso e com desconsideração que a província estaria recebendo do resto do Canadá. Em outras palavras, o aspecto substantivo da demanda por reconhecimento reflete um inconformismo com a desvalorização da identidade ou do status da província e de sua população na relação com o resto do Canadá, colocando-os numa condição de inferiorização inaceitável no plano da cidadania (CARDOSO DE OLIVEIRA, 2011a).

Neste sentido, o debate sobre a legislação linguística no Quebec é aquele que melhor expressa as posições em conflito. Passo agora a uma rápida apresentação de seus aspectos centrais para caracterizar como a questão da identidade ou do status ganha eminência para fundamentar a crítica à

\footnotetext{
7 Tudo isto é amplificado pelo contraste com a oferta plenamente satisfatória de serviços em inglês nas áreas de saúde e educação na província do Quebec, especialmente em Montreal.

${ }^{18}$ Embora uma política ou identidade multiculturalista pareça à primeira vista mais aberta e igualitária do que a alternativa biculturalista defendida pelo Quebec, no caso em tela, em vista da hegemonia da língua/cultura anglo-americana no país como um todo, a opção pelo multiculturalismo foi interpretada no Quebec como um indicador de minorização dos franco-canadenses que desfrutariam assim um status inferior ao dos anglófonos no plano da cidadania. Tal percepção era reforçada por dois outros aspectos: (1) os fortes indicadores de assimilação dos francófonos vivendo nas outras províncias, cuja taxa média seria de 77,3\% em 1991 (BEAUCHEMIN, 1995, p. 31); e (2) o fato de que o governo do Quebec tinha implementado políticas agressivas de integração com respeito e valorização das chamadas "comunidades culturais" dentro de suas próprias fronteiras.
} 
dimensão discriminatória da concepção de igualdade como tratamento uniforme no Canadá.

A derrota no debate sobre biculturalismo e o desenvolvimento da política de afirmação nacional, atravessando todos os governos da província a partir de 1960, aumentaram a percepção sobre a necessidade de proteção da língua francesa no início dos anos 1970, que desembocou na promulgação da Lei no 101, em 1977, após a chegada de René Lévesque e do Partido Quebequense ao poder. A lei impõe três limitações principais ao uso do inglês, as quais afetam o exercício dos direitos individuais dos cidadãos - posteriormente sacralizados na carta de direitos e liberdades anexada à constituição em 1982 - e têm gerado muita polêmica desde então. São estas as limitações:

1) os filhos dos imigrantes, assim como as crianças canadenses cujos pais não estudaram em escola de língua inglesa no Canadá, são obrigados a se matricular em escola de língua francesa;

2) a lei determina que o francês deve ser a língua de trabalho em empresas com mais de 50 empregados, as quais têm um prazo para se adaptar à situação; e,

3) proíbe os letreiros comerciais em outros idiomas (CARDOSO DE OLIVEIRA, 2011a, p. 157).

O primeiro item era mais radical na primeira redação da lei, exigindo que os pais das crianças canadenses tivessem cursado escola de língua inglesa no Quebec, e o terceiro item também foi flexibilizado, passando a permitir letreiros internos bilíngues, e letreiros externos também nas duas línguas, desde que o inglês ocupasse no máximo a metade do espaço ocupado pelo francês, ambas as alterações tendo sido provocadas por intervenção da Suprema Corte canadense. Se é verdade que a limitação referente à matrícula das crianças em escola de língua inglesa afetava todos aqueles cujos pais não haviam estudado em escolas de língua inglesa no Canadá, inclusive os francófonos, que naquele momento também eram pressionados a matricular os filhos nestas últimas devido às maiores oportunidades que estas escolas viabilizavam no mercado 
de trabalho, tal quadro não alterava o fato de que a lei limitava, sim, o direito de escolha de uma parte da população.

De fato, a justificativa frequentemente acionada para a implementação dessas medidas de proteção à língua francesa indica a preocupação com a sua sobrevivência, mas os francófonos falam também na importância de preservar o direito de eles poderem continuar escolhendo viver em francês, rejeitando o que é percebido como processo de imposição do uso do inglês no trabalho e no espaço público, numa sociedade cuja língua da maioria da população é o francês. Durante minha pesquisa em Montreal (de agosto de 1995 a janeiro de 1997) a experiência da obrigação de ter que se comunicar em inglês era relatada de maneira particularmente sofrida por idosos, já aposentados, que não se conformavam com o fato de terem sido prejudicados ao longo de toda vida profissional por terem tido que trabalhar numa língua "estrangeira”, que não dominavam bem (CARDOSO DE OLIVEIRA, 2011a, p. 157) ${ }^{19}$. Além disso, deve-se levar em conta que o debate sobre os direitos linguísticos está marcado por um passado recente no qual se registra vários incidentes de discriminação explícita e ostensiva do francês, quando a população francófona tinha dificuldades de ser atendida em francês nas lojas de departamentos no centro de Montreal, e era tratada com rispidez por vendedores que demandavam: “speak white!” (“fale como branco!” ou “fale inglês!”) (LAURANDEAU, 1990).

Na mesma direção, é importante salientar que o debate linguístico é um importante canal para a discussão de direitos, identidades e cidadania, que constituem aspectos de difícil separação no plano político e no cotidiano dos atores. Basta dizer que toda população do Quebec é classificada linguisticamente em uma das três categorias possíveis, que marcam a língua e o origem das pessoas: francófonos, anglófonos e alófonos. A última categoria inclui todos aqueles que não cabem nas duas primeiras (majoritariamente imigrantes), e tal classificação é cotidianamente acionada para situar as pessoas nas mais diversas situações.

\footnotetext{
19 Na obra citada, eu indico como e porque a população anglófona do Canadá, ou o resto-do-Canadá, tem dificuldades de entender esta percepção de discriminação dos quebequenses, ou a fundamentação das limitações impostas ao uso do inglês pela Lei n 101. Entretanto, minha preocupação neste artigo é demonstrar como na perspectiva do Quebec a lei representa uma garantia de direito e uma demanda de tratamento igualitário.
} 
Assim, os direitos embutidos no debate linguístico aparecem de forma clara e imediatamente inteligível em situações como a da exigência de todos os produtos no supermercado terem rótulos em francês, mas também vem à tona em situações mais surpreendentes, como a do caso do homem cego francófono cujo cão guia era classificado como "anglófono", por receber ordens apenas em inglês. Embora o cego não tivesse qualquer dificuldade de comunicação com o seu cão, o fato dele não ter tido oportunidade de escolher um cão "francófono", que seguisse ordens em francês, foi tomado como uma afronta aos direitos de cidadania da população quebequense nos jornais locais que divulgaram o problema à época, durante meu período mais longo de pesquisa (de agosto de 1995 a janeiro de 1997).

Antes de retomar a discussão sobre cidadania no Brasil na próxima seção, gostaria de enfatizar que o cerne da demanda de reconhecimento do Quebec tem como foco uma equiparação com o resto do Canadá e/ou com os anglófonos no plano do status de cidadania, para a qual se faz necessário a observação institucional do valor ou mérito da singularidade quebequense. Para tanto, seria necessário relativizar o tratamento uniforme no mundo-cívico, sempre que este representasse uma desvalorização da identidade (ou do status da cidadania) quebequense $\mathrm{e}^{20}$. Só assim seria viabilizado um equilíbrio adequado entre direitos, status/identidade e dignidade, sintonizado com a sensibilidade cívica local (quebequense) e, portanto, tornando possível a igualdade cidadã.

A dificuldade de universalização desta visão, entretanto, especialmente no mundo anglófono, é bem expressa na criação no Quebec do Partido da Igualdade, liderado pela comunidade anglófona de Montreal, com o objetivo principal de confrontar a Lei número 101 da língua francesa, pouco depois que esta foi promulgada. Embora este partido tenha perdido muito de sua força política desde sua criação, é importante notar como suas propostas representam bem a visão dominante no resto do Canadá, onde a relativização do tratamento uniforme é entendida como uma demanda de privilégio. Tais propostas

\footnotetext{
${ }^{20}$ Em sua discussão sobre o processo de desenvolvimento dos direitos de cidadania na Inglaterra, Marshall chama atenção para as dificuldades de institucionalizar as primeiras tentativas de garantir acesso a direitos sociais sempre que estes sugeriam uma ameaça ao status igualitário característico da condição de cidadão, como as polêmicas em torno da Poor Law (Lei dos Pobres) indicam (MARSHALL, 1976, p. 22-27).
} 
também explicitam a dificuldade de distinguir e rearticular igualdade de status e igualdade de direitos sempre que a sensibilidade cívica local e o respectivo senso de tratamento digno exigirem uma composição entre estas duas dimensões da cidadania para viabilizar um mundo cívico visto como equânime e bem conformado.

\section{TRANSPARÊNCIA SEM CLAREZA OU NITIDEZ}

Se a tensão entre duas concepções de igualdade torna difícil a identificação de que regra, norma ou lei vale em que contexto, ou mesmo para que categoria social, uma vez que os critérios de aplicação diferenciada destes preceitos normativos não são claros no interior do próprio mundo cívico, a falta de referenciais críveis para o cidadão está presente em quase todos os universos de interação no espaço público ${ }^{21}$, e remete a questões muito mais amplas. Se, após a promulgação da Constituição de 1988 houve uma ampliação substancial da transparência nos processos decisórios do Estado e na definição sobre a alocação de recursos públicos, o mesmo não pode ser dito no que concerne à clareza ou nitidez dos respectivos procedimentos e justificativas. Em outras palavras, embora qualquer cidadão possa acompanhar pela internet quando e para quem os recursos são liberados, não há boas pistas sobre como e por que os critérios de distribuição são definidos e certas decisões são tomadas.

Dois eventos ou processos me parecem particularmente indicativos desta falta de clareza na alocação de direitos e privilégios por um lado, e na definição de políticas públicas por outro: (1) o desenvolvimento da Operação Lava Jato, e (2) as manifestações de 2013. Vou centrar minha discussão no segundo

\footnotetext{
${ }^{21}$ Várias pesquisas realizadas no âmbito do Instituto de Estudos Comparados em Administração de Conflitos (InEAC), da Universidade Federal Fluminense, dão suporte a este diagnóstico quanto à confusão sobre a validade das normas na experiência do cidadão e na arbitrariedade das autoridades do Estado. Seja nos esforços de classificação da "violência policial" (EILBAUM; MEDEIROS, 2015, p. 407-428), nas controvérsias em torno da intolerância religiosa em escolas no Rio de Janeiro (MIRANDA, 2015, p. 139-164), na desqualificação por parte da polícia de moradores de favelas (CARDOSO, 2013, p. 167190; FREIRE; TEIXEIRA, 2016, p. 58-85), ou na classificação de direitos e regalias em presídios no DF (LEMOS, 2017), para citar apenas alguns exemplos.
} 
evento, sem deixar de pontuar dois aspectos importantes da Operação Lava Jato para o meu argumento.

Por ser um processo penal de grande visibilidade, cujas investigações têm como alvo empresários e autoridades públicas de primeira grandeza, usualmente impermeáveis aos braços da lei, a Operação Lava Jato trouxe à tona o padrão de seletividade e de arbitrariedade característicos do nosso processo penal em sentido amplo, até então parcialmente invisibilizado por afetar quase que exclusivamente a população de baixa renda. Para uma descrição balizada e bem argumentada de como este padrão ganha visibilidade no caso da Lava a Jato remeto o leitor ao excelente artigo de Kant de Lima e Mouzinho (2016, p. 505-529) sobre as delações premiadas. No momento, gostaria apenas de chamar a atenção para duas características.

Primeiramente, nota-se o incrível paralelismo entre os discursos dos juristas que têm se colocado contra ou a favor da condenação do ex-presidente Lula no processo do tríplex do Guarujá. Enquanto uns afirmam que as provas seriam incontornáveis ${ }^{22}$, em suporte às decisões efetivamente tomadas pelo Juiz Sérgio Moro e pelos desembargadores do Tribunal Regional Federal da $4^{\mathrm{a}}$ Região, outros afirmam a total falta de provas para fundamentar a condenação $0^{23}$. O fato de ambas as posições serem igualmente lógicas e coerentes reforça a ideia da ausência de critérios compartilhados em nosso sistema judicial para distinguir indícios, evidências e provas como sugere Figueira (2010, p. 297-322). Isto significa que, aparentemente, não há critérios que permitam uma decisão fundamentada, não arbitrária, para um lado ou para o outro, que passe pelo crivo de procedimentos argumentativos. Neste sentido, o caráter opinativo e não argumentativo do nosso contraditório judicial tem sido assinalado por vários colegas que fazem pesquisa empírica sobre processos judiciais ${ }^{24}$, mas agora ganha manchetes nos jornais e chega ao público em geral.

\footnotetext{
${ }^{22}$ Como exemplo, "as provas que basearam a decisão do TRF-4", disponível em: https://goo.gl/YNpvRR. Conferir também: "Veja repercussão de juristas sobre condenação de Lula em $2^{\mathrm{a}}$ instância", disponível em: https://goo.gl/egvWWX. Acesso em: 26 set. 2008.

${ }^{23}$ Por exemplo, “Juristas são unânimes: não há provas contra Lula", disponível em: https://goo.gl/SzQhRx. Acesso em: 26 set. 2018.

${ }^{24}$ Veja, entre outros, os trabalhos de Kant de Lima (1995 e 2008), Amorim (2006, p. 107-108), Amorim, Kant de Lima e Teixeira Mendes (2005, p. xi-xxxviii), Teixeira Mendes (2012) e Lupetti Batista (2013).
} 
A segunda característica geral que eu gostaria de indicar é a tensão entre as perspectivas inquisitorial e garantista em nossa tradição jurídica. Ainda que esta última esteja mais próxima da dimensão acusatória de nosso sistema, concebido como misto, já que o inquérito policial é inquisitorial, sem contraditório (KANT DE LIMA; MOUZINHO, 2016), a articulação entre as duas perspectivas tem significado uma expressão particularmente perversa da tensão entre as duas concepções de igualdade indicadas acima, na medida em que o acesso ao garantismo tem sido restrito à população mais abasta$\mathrm{da}^{25}$. Esta, com apoio de bons advogados, frequentemente consegue se beneficiar de falhas processuais na investigação para eliminar "provas” e escapar das respectivas acusações, ou aciona intermináveis recursos processuais até a prescrição do crime. De certa forma, é como se a condenação quase certa dos pobres devido à dificuldade de provar a inocência frente à inquisitorialidade do inquérito policial, cujo indiciamento (sem contraditório) tem fé pública, fosse invertida no caso daqueles que podem pagar bons advogados, frente a amplas possibilidades de manipulação dos princípios garantistas no processo judicial.

Como sugerem Kant de Lima e Mouzinho (2016), ao mesmo tempo em que a atuação integrada da Polícia Federal e do Ministério Público, como força-tarefa, diminuiu muito a possibilidade de identificação das referidas falhas processuais na Operação Lava Jato ${ }^{26}$, o caráter inquisitorial do processo penal também foi acentuado, inclusive no que concerne às delações premiadas. De todo modo, a dimensão de arbitrariedade envolvida nestes procedimentos passou a fazer parte do debate público, contribuindo para a insatisfação social com a falta de clareza.

\footnotetext{
${ }^{25}$ Apenas como exemplo, em novembro de 2006 uma juíza do Rio de Janeiro autorizou um mandado de busca e apreensão coletivo na Cidade de Deus depois que um helicóptero da polícia militar teria sido derrubado por traficantes na localidade, em total desrespeito ao Código de Processo Penal que prevê a necessidade do mandado especificar o endereço e o morador, assim como os limites da busca. Disponível em: https://goo.gl/vbQXj7. Acesso em: 24 set. 2018. Ainda que o mandado tenha sido posteriormente revogado, ele só havia sido concedido por se tratar de uma "favela", ou comunidade de baixa renda, caracterizando o padrão de dois pesos e duas medidas nesta matéria.

${ }^{26}$ Além disso, no caso dos acusados com prerrogativa de foro por função (vulgo foro privilegiado) o STF passou a conjugar as funções de primeira e última instância ao mesmo tempo, eliminando possibilidades de recurso e de prescrição dos respectivos crimes.
} 
Não obstante, a demanda por maior clareza na definição das políticas públicas apareceu com maior ênfase e nitidez nas manifestações de junho de 2013. Tendo iniciado como um protesto contra aumentos nas passagens de ônibus e metrô no Rio de Janeiro e em São Paulo, sob a liderança do Movimento Passe Livre, as manifestações ampliaram-se e espalharam-se rapidamente por todo o país de forma razoavelmente espontânea, por meio das redes sociais, sem liderança definida, e tendo como foco a demanda por melhores serviços públicos de uma maneira geral, além de críticas à corrupção, que já era percebida como um problema grave à época ${ }^{27}$. As manifestações coincidiram com o início da Copa das Confederações, e os vultosos recursos investidos na infraestrutura para esta copa, assim como para a Copa do Mundo e para as Olimpíadas de 2016 que se realizariam nos anos seguintes, acabaram dando o mote das palavras de ordem e contestações, ao serem comparados com a percepção de baixo investimento na melhoria dos serviços públicos nas áreas de saúde e educação.

As demandas e palavras de ordem expostas nos cartazes empunhados pelos manifestantes dão uma boa ideia do conteúdo das críticas e do bom humor que também caracterizou as manifestações, apesar da dura repressão em alguns momentos:

- "Desculpem o transtorno: estamos mudando o país";

- "Não é Turquia, não é a Grécia, é o Brasil despertando da inércia";

- "Saí do Face";

- "Turkey is here";

- "Você acordou agora, a periferia nunca dormiu";

- "Queremos saúde e educação padrão FIFA";

- "É muito motivo, não cabe aqui!";

- "Eu quero: ( ) Tchu; ( ) Tcha; (x) 10\% do PIB para a Educação";

27 As críticas contra a corrupção seriam muito ampliadas no ano seguinte, com a explosão de informações sobre as investigações da Operação Lava Jato. 
- “IgUALITE, LIBERTE, FRATERNITÉ, VINAGRÉ";

- "YES PACMAN; NO PEC 37";

- “Transporte Público Pior que a TIM!”;

- "Senhor PM, minha mãe disse para não aceitar balas de borracha de estranhos!”.

Embora as manifestações tenham pegado a todos de surpresa, vários autores esboçaram interpretações interessantes para a indignação popular que motivou os eventos. Tendo como referência a questão da mobilidade urbana, Caldeira (2013) indicou a demanda de acesso à cidade, enquanto Soares (2013), Kant de Lima e Pires (2014) entenderam as reivindicações como produto da recente ampliação no acesso a direitos, os dois últimos enfatizando a ampliação do acesso à renda e à educação superior, que teriam tornado mais exigente este segmento da população, constituindo uma nova classe média. Castells (2013), por seu turno, contextualizou o processo na crise de representação mais ampla, afetando as democracias representativas em toda a parte, e salientando a demanda do cidadão de ser ouvido. De modo similar, Soares (2013) também assinala a falta de canais de comunicação com o movimento social, que teria sido cooptado pelos governos do PT.

Sem discordar destas interpretações, a meu ver a principal mensagem destas manifestações se traduz numa demanda de esclarecimento sobre os critérios de alocação de recursos nas políticas públicas, tendo como pano de fundo o que Kant de Lima e Pires (2014, p. 38) chamaram de desnaturalização da desigualdade na esfera pública, a qual, no contexto de minha discussão, sinalizaria um agravamento da tensão entre as duas concepções de igualdade caracterizadas acima, e a confusão entre direitos e privilégios. Na mesma direção, naquilo que as jornadas de junho seriam similares a movimentos sociais em outras partes do mundo, demandando maior participação nas democracias representativas vigentes, como as reivindicações do Podemos na Espanha ou o Occupy Wall Street em Nova York, e que eu caracterizaria como demandas de inclusão discursiva, é importante indicar que a exclusão brasileira não 
se limita a uma dificuldade de ouvir adequadamente o cidadão, mas estaria marcada por uma desvalorização da opinião de segmentos expressivos da população, frequentemente classificados como hipossuficientes em dois sentidos: (1) por não terem recursos para levar suas causas adiante sem apoio do Estado; e, (2) por não conhecerem seus direitos e, portanto, não estando em condições de fazer escolhas ou de tomar decisões por si próprios (CARDOSO DE OLIVEIRA, 2018, p. 11-12).

Assim como a crítica à corrupção se intensifica exatamente no momento em que o Estado aperfeiçoa os instrumentos para combatê-la, ainda que isto não signifique sucesso nos esforços para diminuir a incidência destas práticas, as demandas por clareza ou esclarecimento também se ampliam no momento em que há maior transparência nos gastos públicos e que o cidadão pôde experimentar situações nas quais teria sido efetivamente mais ouvido. Numa palavra, o aumento da transparência, especialmente a partir do governo Itamar Franco, a elucidação dos escândalos de corrupção e o tratamento desigual, produto da tensão entre as duas concepções de igualdade, ao lado da falta de clareza na alocação de direitos, privilégios e recursos públicos, passaram a ferir a dignidade do cidadão e teriam estimulado as manifestações.

Mas, vários acontecimentos nos últimos trinta anos teriam contribuído para esta indignação com a falta de clareza entre direitos e privilégios por um lado, e nos critérios para alocação de recursos públicos de outro. Se o período constituinte foi marcado por grande mobilização popular em torno da discussão dos direitos e garantias que permitiriam superar as arbitrariedades do período de exceção, formalmente findo com a eleição de Tancredo Neves em 1985, o impeachment do presidente Collor foi vivido como um momento de participação efetiva da cidadania. Da mesma forma, a chegada e a consolidação do Plano Real na segunda metade dos anos 1990 trouxe não só uma ampliação significativa no acesso à renda, mas viabilizou uma compreensão muito mais rica da condição social do cidadão, que agora podia ter uma ideia mais clara do valor dos bens oferecidos no mercado, assim como de sua renda e do significado dos recursos alocados pelo Estado. Pois, numa economia capitalista, onde o mercado é formador dos preços e quase tudo pode ser precificado, a inflação 
alta faz com que a população perca todos os referenciais para avaliar o valor das coisas, das situações e das relações sociais de uma maneira geral.

Além disso, as experiências de orçamento participativo nas prefeituras do PT e no governo do DF também nos anos 1990 viabilizaram e visibilizaram oportunidades efetivas de participação do cidadão na gestão pública, independentemente das polêmicas suscitadas sobre a compatibilidade desta participação com os princípios da democracia representativa e dos direitos da maioria que não pode ser ouvida nesta consulta direta para definição do orçamento. Se somarmos a esta lista de acontecimentos a já mencionada ampliação do acesso ao ensino superior nos governos Lula, os programas alinhados à ideia de renda mínima iniciados nos governos de FHC (Bolsa Escola) e significativamente ampliados nos governos Lula (Bolsa Família), temos uma verdadeira revolução no que concerne à ampliação no acesso a direitos e à participação na vida democrática da nação, ainda que o resultado disto tudo esteja muito aquém das necessidades sociais e do que seria desejado. Não obstante, o ponto aqui é que neste novo quadro a sociedade tem se tornado muito mais sensível às arbitrariedades do Estado e à ausência de justificativas discursivas para a confusão entre os campos semânticos de direitos e privilégios. Assim, a sensibilidade cívica vigente fica ferida e a insatisfação com o mundo cívico mal conformado é agravada.

Gostaria de concluir o artigo com um último exemplo sobre a ausência de fronteiras claras entre o universo de vigência de direitos e privilégios, não apenas para enfatizar a abrangência do problema, mas também para chamar atenção para a dissintonia entre moralidade societária (com referência à normatividade nas relações entre todos os cidadãos, contando com o respaldado do Estado) e moralidade comunitária (com referência à normatividade nas relações interpessoais) no Brasil. Trata-se de dois pares de categorias, assim como descritos e analisados na tese de Carolina Lemos (2017) sobre presídios no DF: (1) direitos e regalias; e, (2) puxar pena versus pagar pena.

Embora as categorias nativas de direitos e regalias sugiram uma aproximação clara com a minha discussão sobre a relação entre direitos e privilégios, seus conteúdos semânticos são excessivamente próximos, indicando 
não apenas a dificuldade de distingui-las no plano conceitual, mas o caráter arbitrário de seu acionamento, especialmente quando a classificação aparece imposta por autoridades do presídio. Enquanto as demandas por direitos das presas frequentemente não tem fundamento na Lei de Execução Penal (LEP), como a solicitação de troca de ala feita por Helena, uma das interlocutoras de Lemos na pesquisa, direitos previstos em lei como "o acesso a trabalho remunerado (Art. 41, II), à assistência escolar (Art. 41, VII) e o direito de receber visitas Art. 41, X)" eram classificados como regalias" (Lemos, 2017, p. 113). Vale dizer, entretanto, que a demanda de Helena era baseada no seu bom comportamento e nas regras informais de avaliação de mérito impessoal vigentes no presídio, em alguma medida similar à perspectiva universalista usualmente atribuída à noção de direitos, mas que no presídio é implementada de forma abertamente arbitrária. Uma implicação relevante do caráter arbitrário neste e em outros contextos é a consequente desvalorização do interlocutor, aqui tomado como alguém que não merece justificativas ou satisfações do Estado.

Na mesma direção, enquanto a ideia de puxar pena assinala o caráter punitivo da ação do Estado, associado a um padrão sistemático de desrespeito à pessoa dos presos, sem qualquer conteúdo pedagógico, não estimulando qualquer mudança ou atitude reflexiva na população carcerária, a noção de pagar pena é associada a ideias de reparação e dever moral, como no caso de Anderson, por exemplo. O caso dele é particularmente interessante porque, apesar de ter sido condenado por um crime que não cometeu, teria considerado "o julgamento justo em razão de outros crimes do passado pelos quais não havia pago: o que você deve um dia você tem que pagar, né?" (LEMOS, 2017, p. 177). Enquanto o encarceramento como punição e expresso na ideia de puxar pena só provoca sofrimento e deixa as pessoas mais revoltadas, na visão dos presos, a ideia de pagar pena traduz uma obrigação moral e tem um conteúdo de reparação. A propósito, sempre que a experiência na prisão é associada pelos presos a alguma dimensão de aprendizado ou de reparação, os exemplos acionados têm como referência relações interpessoais, especialmente no âmbito da família. 
Tal quadro sugere a possibilidade e a preocupação de reinserção na comunidade moral, mas sem apoio ou respaldo das instituições do Estado, visto que aos olhos dos presos o encarceramento não serve para nada. Isto é, o discurso sobre reparação moral não faz menção aos crimes que teriam cometido ou às pessoas que teriam lesado, mas às suas relações no âmbito comunitário ou familiar. Os casos de Helena e Anderson descritos por Lemos (2017), vividos numa instituição total, sem maiores preocupações com a aceitação pública de suas regras de funcionamento, realçam os dilemas da cidadania na sociedade mais ampla, onde a confusão entre direitos e privilégios suscita questionamentos cada vez mais frequentes quanto à legitimidade das decisões do Estado. Aqui também aparece, com maior dramaticidade, os problemas vividos por uma sociedade moderna com um mundo cívico mal conformado, sem clareza nos critérios de alocação de direitos e privilégios, e tendo como implicação grande dificuldade de sintonização de suas normas com a sensibilidade cívica vigente.

\section{REFERÊNCIAS}

1. AMORIM, Maria Stella. Juizados Especiais na região metropolitana do Rio de Janeiro. Revista da Seção Judiciária do Rio de Janeiro, Rio de Janeiro, v. 17, p. 107-131, ago. 2006.

2. AMORIM, Maria Stella; KANT DE LIMA, Roberto; TEIXEIRA MENDES, Regina Lúcia. "Introdução". In: AMORIM, Maria Stella; KANT DE LIMA, Roberto; TEIXEIRA MENDES, Regina Lúcia (org.). Ensaios sobre a igualdade jurídica. Rio de Janeiro: Lumen Juris, 2005. p. 11-38.

3. BARBOSA, Rui. Oração aos moços. Rio de Janeiro: Edições Casa Rui Barbosa, 1999.

4. BARRETO, Fabiana. Flagrante e prisão provisória em casos de furto. São Paulo: Ibccrim, 2007.

5. BEAUCHEMIN, Yves. Petite histoire du Québec. Montreal: Uneq, 1995.

6. BIBEAU, Gilles. Tropisme québécois. Je me souviens dans loubli . Anthropologie et Sociétés, v. 19, n. 3, p.151-198, 1995. 
7. CALDEIRA, Teresa. São Paulo: the city and its protests. Open Security: conflict and peacebuilding, 11 jul. 2013. Disponível em: https://goo.gl/CuxYiV. Acesso em: 8 out. 2018.

8. CARDOSO, Marcus. A dimensão simbólica dos conflitos: moradores de favela e polícia. Anuário Antropológico, Brasília, DF, 2012/I, p. 167-190, 2013.

9. CARDOSO DE OLIVEIRA, Luís R. Fairness and communication in small claims courts. 1989. Dissertação (Mestrado em Antropologia) - Universidade de Harvard, Cambridge, 1989.

10. CARDOSO DE OLIVEIRA, Luís R. Entre o justo e o solidário: Os dilemas dos direitos de cidadania no Brasil e nos EUA. Revista Brasileira de Ciências Sociais, v. 11, n. 31, p. 67-81, 1996.

11. CARDOSO DE OLIVEIRA, Luís R. Direito legal e insulto moral: dilemas da cidadania no Brasil, Quebec e EUA. 2. ed. Rio de Janeiro: Garamond, 2011 a.

12. CARDOSO DE OLIVEIRA, Luís R. Concepções de igualdade e (des)igualdades no Brasil. In: LIMA, Roberto Kant de; EILBAUM, Lucia; PIRES, Lenin. (org.). Conflitos, direitos e moralidades em perspectiva comparada. v. 1. Rio de Janeiro: Garamond, 2010, p. 19-33.

13. CARDOSO DE OLIVEIRA, Luís R. Concepções de igualdade e cidadania. Contemporânea: Revista de Sociologia da UFSCar, São Carlos, n. 1, p. 35-48, 2011b.

14. CARDOSO DE OLIVEIRA, Luís R. Equality, dignity and fairness: Brazilian citizenship in comparative perspective. Critique of Anthropology, v. 33, n. 2, p. 131-145, 2013.

15. CARDOSO DE OLIVEIRA, Luís R. Desvendando Evidências Simbólicas: compreensão e conteúdo emancipatório da Antropologia. Rio de Janeiro: Editora da UFRJ, 2018.

16. CASTELLS, Manuel. O povo não vai se cansar de protestar. O Globo, Rio de Janeiro, 28 jul. 2013. Disponível em: https://goo.gl/uUZLbd. Acesso em: 8 out. 2018.

17. DAMATTA, Roberto. Você sabe com quem está falando? um ensaio sobre a distinção entre indivíduo e pessoa no Brasil. In: DAMATTA, Roberto. Carnavais, malandros e heróis: para uma sociologia do dilema brasileiro. Rio de Janeiro: Zahar Editores, 1979, p. 139-193.

18. D'IRIBARNE, Philippe. Létrangeté française. Paris: Éditions du Seuil, 2006.

19. D'IRIBARNE, Philippe. Les immigrés de la République: impasses du multiculturalisme. Paris: Éditions du Seuil, 2010. 
20. EILBAUM, Lucía; MEDEIROS, Flavia. Quando existe violência policial? Direitos, moralidades e ordem pública no Rio de Janeiro. Dilemas: Revista de Estudos de Conflito e Controle Social, v. 8, n. 3, p. 407-428, 2015.

21. FIGUEIRA, Luiz Eduardo. Prova no tribunal do júri brasileiro: o império da moral nas decisões não fundamentadas. Revista Ciências Sociais, Rio de Janeiro, v. 16, p. 297-322, 2010.

22. FREIRE, Jussara; TEIXEIRA, Cesar Pinheiro. Humanidade disputada: sobre as (des)qualificações dos seres no contexto de "violência urbana" no Rio de Janeiro. Terceiro Milênio: Revista Crítica de Sociologia e Política, v. 6, n. 1, p. 58-85, 2016.

23. GEERTZ, Clifford. Local knowledge: further essays in interpretive anthropology. New York: Basic Books, 1983.

24. GROULX, Lionel. L’Appel de la race. Montreal: Fides, 1956.

25. HONNETH, Axel. The other of justice: Habermas and the ethical challenge of postmodernism. In: HONNETH, Axel (ed.). Disrespect: the normative foundations of critical theory. Cambridge: Polity Press, 2007. p. 99-128.

26. KANT DE LIMA, Roberto. Da inquirição ao júri, do trial by jury à plea bargaining: modelos para a produção da verdade e a negociação da culpa em uma perspectiva comparada Brasil/Estados Unidos. 1995. Tese (Concurso de Professor Titular em Antropologia) - Departamento de Antropologia, Universidade Federal Fluminense, Niterói, 1995.

27. KANT DE LIMA, Roberto. Ensaios de antropologia e direito. Rio de Janeiro: Lumen Juris, 2008.

28. KANT DE LIMA, Roberto; MOUZINHO, Glaucia Maria Pontes. Produção e reprodução da tradição inquisitorial no Brasil: entre delações e confissões premiadas. Dilemas: Revista de Estudos de Conflito e Controle Social, v. 9, n. 3, p. 505-529, 2016.

29. KANT DE LIMA, Roberto; PIRES, Lenin. A difícil convivência entre mudanças sociais dirigidas e recorrentes formas de administrar conflitos entre juridicamente desiguais no Brasil. Enfoques, v. 13, n. 1, p. 33-42, 2014.

30. LAFOREST, Guy. Trudeau and the end of a Canadian Dream. Montreal: McGillQueen's University Press, 1995.

31. LAURENDEAU, André. Journal tenu pendant la Commission royale d'enquête sur le bilinguisme et le biculturalisme. Québec: VLB Éditeur; Le Septentrion, 1990.

32. LEGAULT, Josée. L'Invention d'une minorité: les anglo-québécois. Québec: Boréal, 1992. 
33. LEMOS, Carolina. Puxando pena: sentidos nativos da pena de prisão em cadeias do Distrito Federal. 2017. Tese (Doutorado em Direito) - Universidade de Brasília, Brasília, DF, 2017.

34. LUPETTI BATISTA, Bárbara. Paradoxos e ambiguidades da imparcialidade judicial - entre "quereres" e "poderes". Porto Alegre: Núria Fabris, 2013.

35. MARSHALL, T. H. Class, citizenship and social development. Westport: Greenwood Press, 1976.

36. 36. MIRANDA, Ana Paula. Motivo presumido: sentimento: identidade religiosa e estigmatização escolar do Rio de Janeiro. Dilemas: Revista de Estudos de Conflito e Controle Social, Edição Especial, n. 1, p. 139-164, 2015.

37. MOTA, Fábio Reis. Cidadãos em toda parte ou cidadãos à parte? Demandas de direitos e reconhecimento no Brasil e na França. Rio de Janeiro: Consequência, 2014.

38. SANDEL, Michael. The procedural republic and the unencumbered self. Political Theory, Sage Publications, v. 12, n. 1, p. 81-96, 1984.

39. SOARES, Luiz Eduardo. O que vem depois da queda da tarifa? O Globo, Rio de Janeiro, 22 jul. 2013. Disponível em: https://goo.gl/Vk8heC. Acesso em: 24 jul. 2013.

40. TAYLOR, Charles. The politics of recognition. In: GUTMANN, A. (ed.). Multiculturalism and "The Politics of Recognition". Princeton: Princeton University Press, 1994, p. 25-73.

41. TEIXEIRA MENDES, Regina Lúcia. Do princípio do livre convencimento motivado: legislação, doutrina e interpretação de juízes brasileiros. Rio de Janeiro: Lumen Juris, 2012.

42. TEIXEIRA MENDES, Regina Lúcia. Igualdade à brasileira: cidadania como instituto jurídico no Brasil. In: AMORIM, Maria Stella; KANT DE LIMA, Roberto; TEIXEIRA MENDES, Regina Lúcia (org.). Ensaios sobre a Igualdade Jurídica: acesso à justiça criminal e direitos de cidadania no Brasil. Rio de Janeiro: Lumen Juris, 2005. p. 1-33. 